\title{
Isolated abducens nerve palsy in preeclampsia and hypertension in pregnancy
}

\author{
Hypertension Research (2013) 36, 834-835; doi:10.1038/hr.2013.50; published online 30 May 2013
}

Preeclampsia-related neurological disorders are well established but have a broad spectrum of manifestations, from just headache to major events. Nevertheless, disorders of cranial nerves are rare in preeclampsia.

A 36-year-old pregnant woman, with a history of obesity and a prior pregnancy 2 years earlier that ended in the 28th week because of severe preeclampsia, came to the emergency department in the 36th week of her new gestation. She complained of a $48-\mathrm{h}$ frontal headache accompanied by diplopia upon looking to the left in the last $24 \mathrm{~h}$.

The patient was evaluated at the beginning of the current gestation and was advised to take aspirin $100 \mathrm{mg}$ per day from the 12th week of gestation. She had no history of diabetes, head injury, fever or any dural procedure during pregnancy. She had been diagnosed with gestational hypertension without proteinuria 3 weeks earlier and then treated with methyldopa $250 \mathrm{mg}$ per $8 \mathrm{~h}$, at which point the patient discontinued the aspirin. At admission, the patient had hypertension $(156 / 95 \mathrm{~mm} \mathrm{Hg})$. An examination, including fundoscopy, was completely normal except for reduced ocular abduction to the left, consistent with left sixth cranial nerve palsy. Her blood pressure (BP) was controlled with methyldopa $500 \mathrm{mg}$ per $8 \mathrm{~h}$, and when the levels increased, we added hydralazine $5 \mathrm{mg}$ intravenously. Despite controlling the BP, during the follow-up, the headache and visual symptoms persisted. In addition, the patient developed proteinuria of up to $2.4 \mathrm{~g}$ within $24 \mathrm{~h}$. Her platelet count decreased from $227000 \mu \mathrm{l}^{-1}$ to $144000 \mu \mathrm{l}^{-1}$, and her uric acid concentration was $7.5 \mathrm{mg} \mathrm{dl}^{-1}$. A computerized tomography scan of the brain was normal. On the basis of these data, on the second day after admission, a cesarean section was performed, and a healthy $2.56-\mathrm{kg}$ girl was delivered.
Upon follow-up after the delivery, the headache disappeared and the diplopia began to improve spontaneously, with remaining left sixth cranial nerve paresis. The BP was controlled with labetalol $200 \mathrm{mg}$ per $8 \mathrm{~h}$, and the biochemical parameters progressively returned to normal. A magnetic resonance imaging of the brain was normal. The patient's vision gradually improved, and 12 weeks after discharge, she had recovered completely. Her BP was normal $(115 / 85 \mathrm{~mm} \mathrm{Hg})$ without treatment.

\section{DISCUSSION}

Isolated sixth cranial (abducens) nerve disorder is a rare condition associated with gestation, and very few cases have been reported (see Table 1). Most of these cases are related to hypertension, and mainly preeclampsia.

In general, among the nonpregnant young adult population, the etiology of isolated sixth cranial nerve palsy is controversial (in contrast with older adults, where a microvascular disease associated with hypertension, diabetes or other atherosclerosis-related factors is presumed to be the most frequent cause $^{1,2}$ ). In young adults (aged 15-20 to 50 years), different results have been shown in previous retrospective studies of nontraumatic isolated sixth cranial nerve palsies. In a study by Moster et al., ${ }^{1}$ vasculopathy was the most frequent cause (29\% of cases), followed by an undetermined cause in $22 \%$ of patients. However, in a report by Peters et al., ${ }^{2}$ the most likely etiology was multiple sclerosis (33\% of cases), followed by idiopathic (18\%), postviral (12\%) and central nervous system mass (9\%). Differences in both studies can be mainly because of the fact that the first series was carried out before the routine use of magnetic resonance imaging, so these patients did not undergo such tests.
The exact cause of this palsy related to pregnancy remains unknown. Different theories have been suggested to explain this disorder in association to the hypertensive disease in pregnancy. The nerve abducens innervates the lateral rectus extraocular muscle and is responsible for horizontal conjugate gaze. ${ }^{3}$

Certain authors have suggested a downward displacement of the nerve due to increased intracranial pressure and nerve ischemia, such as in the case of cerebral edema. ${ }^{4,5}$ However, this disorder, and especially cerebral edema, usually supposes a more complex clinical picture. In addition, to diagnose isolated sixth cranial nerve palsy, it is necessary to exclude the presence of other neurological symptoms or signs. ${ }^{3}$ Thus, the case reported by Blade et al. $^{4}$ (see Table 1), although related to eclampsia, cannot be considered to be a truly isolated palsy because other neurological signs occurred at the same time. A more complex neurological disorder is therefore presumed.

Other authors consider the disorder to be secondary to hypertension, with vasospasm of the vessels to the nerve and ischemia. ${ }^{6-8}$ We are more in agreement with this notion because no other neurological data are found to consider intracranial pressure elevation or other disorders. In addition, considering that (1) posterior and basilar arterial circulation appear to be especially susceptible to vasospasm, (2) focal or diffuse vasospasm has been related to preeclampsia, and (3) the nucleus of the nerve is in the lower dorsal pons and the nerve has a course dependent on this arterial bed, we hypothesize that vasospasm in this circulation, secondary to preeclampsia and leading to transient ischemia, is most likely the cause of the case that we report and of other previously described cases. 
Table 1 Reported cases of isolated sixth cranial nerve palsy associated to pregnancy and not related to lumbar procedure

\begin{tabular}{|c|c|c|c|c|c|c|c|}
\hline Reference & $\begin{array}{c}\text { Age } \\
\text { (years) }\end{array}$ & Primiparity & $\begin{array}{l}\text { Preeclampsia } \\
\text { in previous } \\
\text { gestation }\end{array}$ & Onset date (palsy) & Diagnosis & Time of recovery & Comments \\
\hline Blade et al. (1968) a & 22 & Yes & - & $\begin{array}{l}\text { Postpartum onset } \\
(<24 \mathrm{~h})\end{array}$ & Eclampsia & 6 months & $\begin{array}{l}\text { Delivery at } 40 \text { weekś gestation. } \\
\text { Coma, increased intracranial } \\
\text { and intraocular pressure, vasos- } \\
\text { pasms of retinal arterial vessels, } \\
\text { pronounced neurological deficit. }\end{array}$ \\
\hline $\begin{array}{l}\text { Sternberg et al. } \\
(1980)^{\mathrm{b}}\end{array}$ & 25 & Yes & - & 6 months & $\begin{array}{l}\text { Normal blood pressure. } \\
\text { Post-febrile disease } \\
\text { ( } 2 \text { weeks earlier) }\end{array}$ & 3 months & $\begin{array}{l}\text { Recurrent, isolated, post-febrile } \\
\text { episodes (at age } 3 \text { and } 13 \text { years } \\
\text { old). }\end{array}$ \\
\hline $\begin{array}{l}\text { Barry-Kinsella et al. } \\
(1994)^{7}\end{array}$ & 33 & No & No & 38 weeks & Preeclampsia & 2 weeks & Frontal headache. \\
\hline Fung et al. $(1999)^{8}$ & 26 & No & No & 38 weeks & $\begin{array}{l}\text { Late no proteinuric transi- } \\
\text { ent gestational hypertension }\end{array}$ & 6 days & No headache. \\
\hline $\begin{array}{l}\text { Thurtell et al. } \\
(2006)^{6}\end{array}$ & 35 & No & No & $\begin{array}{l}\text { Postpartum onset } \\
\text { (11 days) }\end{array}$ & $\begin{array}{l}\text { Preeclampsia epidural } \\
\text { anesthesia }\end{array}$ & $\begin{array}{l}\text { Slowly resolve in } \\
\text { months after } \\
\text { discharge }\end{array}$ & $\begin{array}{l}\text { Delivery at } 30 \text { weekś gestation. } \\
\text { Headache. History of untreated } \\
\text { white coat hypertension. }\end{array}$ \\
\hline $\begin{array}{l}\text { Thamban et al. } \\
(2006)^{10}\end{array}$ & 34 & No & No & 40 weeks & $\begin{array}{l}\text { Normal blood pressure. } \\
\text { Uneventful gestation. }\end{array}$ & 6 weeks & No headache. \\
\hline Park et al. $(2007)^{5}$ & 33 & No & No & $\begin{array}{l}\text { Postpartum onset } \\
(<24 \mathrm{~h})\end{array}$ & Preeclampsia & 7 days & $\begin{array}{l}\text { Delivery at } 39 \text { weekś gestation. } \\
\text { Headache. Fetal growth } \\
\text { retardation. }\end{array}$ \\
\hline Case report & 36 & No & Yes & 36 weeks & Preeclampsia & $<12$ weeks & Frontal headache. \\
\hline
\end{tabular}

Most cases are related to hypertension during pregnancy, mainly preeclampsia, with high variability in the different variables. Only in the case we report the patient had a prior history of preeclampsia in a previous gestation. The palsy can also appear after delivery. In every case there was a complete recovery.

Search strategy: MEDLINE; no limits; last search 6 December, 2012; search terms: we used different combinations of the following MeSH terms: 'cranial nerve diseases', 'abducens nerve diseases', 'pregnancy', 'preeclampsia', 'hypertension, pregnancy-induced', and also related free terms; we also revised references in the articles we considered. ${ }^{4-8,10}$

aThis case cannot be considered as a truly isolated abducens nerve palsy, as other neurological signs occurred at the same time; so it can be considered as part of a more complex neurological disorder and took a long time to recover.

disorder and took a long time to recover. comment it).

Cases of sixth cranial nerve palsy secondary to dural puncture (such as spinal anesthesia), although infrequent, are well established. ${ }^{1,3,9}$ Intracranial hypotension, with the descent of cerebral structures and consequent traction and stretching of the nerve (causing local ischemia and nerve dysfunction), is thought to be the cause of the disorder in these cases. ${ }^{9}$ In the case reported by Thurtell et al. ${ }^{6}$ (see Table 1), the patient presented with preeclampsia, but in addition, epidural anesthesia was performed before cesarean section. The onset of sixth nerve palsy occurred on day 11 after delivery. It has been described that diplopia as manifestation of nerve palsy after spinal anesthesia use to appear with a mean of 10 days. ${ }^{3,9}$ Thus, in the case of Thurtell et al., ${ }^{6}$ although preeclampsia and an ischemic etiology are considered to be most likely, a postdural puncture etiology or a combined mechanism cannot be excluded.

As in the case that we report, the prognosis appears to be benign, with a complete recovery of the palsy in all reported cases associated with pregnancy-related hypertension (although there is a significant variability in the time of recovery). Despite that characteristic, we believe that a computerized tomography or magnetic resonance imaging of the brain must be undertaken to exclude intracranial lesions or edema. In the case of no features in radiological imaging, clinical monitoring is most likely sufficient when the palsy is clearly related to hypertension or preeclampsia and the disorder progressively improves.

\section{CONFLICT OF INTEREST}

The authors declare no conflict of interest.

Antonio J Vallejo-Vaz, Pablo Stiefel, Verónica Alfaro and María L Miranda

Unit of Hypertension, Department of Internal Medicine, Virgen del Rocío University Hospital, and Instituto de Biomedicina (IBiS), Sevilla, Spain E-mail: ajvallejo@hotmail.com
1 Moster ML, Savino PJ, Sergott RC, Bosley TM, Schatz NJ. Isolated sixth-nerve palsies in younger adults. Arch Ophthalmol 1984; 102: 1328-1330.

2 Peters GB, Bakri SJ, Krohel GB. Cause and prognosis of nontraumatic sixth nerve palsy in young adults. Ophthalmology 2002; 109: 1925-1928.

3 Brazis P. Isolated palsies of cranial nerves III, IV and VI. Semin Neurol 2009; 29: 14-28.

4 Bladé J, Peborde J, Darleguy P. Paralysie du VI au cours dune éclampsie. Bull Soc Ophtalmol Fr 1968; 68: 284-287.

5 Park CM, Kim SY. Abducens nerve palsy in preeclampsia after delivery: an unusual case report. J Obstet Gynaecol Res 2007; 33: 543-545.

6 Thurtell MJ, Sharp KL, Spies JM, Halmagyi GM. Isolated sixth cranial nerve palsy in preeclampsia. J Neuro-Ophthalmol 2006; 26: 296-298.

7 Barry-Kinsella C, Milner M, McCarthy N, Walshe J. Sixth nerve palsy: an unusual manifestation of preeclampsia. Obstet Gynecol 1994; 83: 849-851.

8 Fung TY, Chung TKH. Abducens nerve palsy complicating pregnancy: a case report. Eur J Obstet Gynecol Reprod Biol 1999; 83: 223-224.

9 Quraishi SA. Abducens palsy following spinal anesthesia: mechanism, treatment and anesthetic considerations. MedGenMed 2005; 7: 16.

10 Thamban S, Nama V, Sharma R, Kollipara PJ. Abducens nerve palsy complicating pregnancy. J Obstet Gynaecol 2006; 26: 811-812.

11 Sternberg I, Ronen S, Arnon N. Recurrent, isolated, post-febrile abducens nerve-palsy. J Pediatr Ophthalmol Strabismus 1980; 17: 323-324 (abstract). 